\title{
Small UAV Research and Evolution in Long Endurance Electric Powered Vehicles
}

\author{
Michael J. Logan ${ }^{1}$, Julio Chu ${ }^{2}$, Mark A. Motter ${ }^{3}$ \\ NASA Langley Research Center, Hampton, VA 23681 \\ Dennis L. Carter ${ }^{4}$, Michael Ol ${ }^{5}$, Cale Zeune ${ }^{6}$ \\ USAF Air Force Research Laboratory, WPAFB, OH, 1111
}

\begin{abstract}
This paper describes recent research into the advancement of small, electric powered unmanned aerial vehicle (UAV) capabilities. Specifically, topics include the improvements made in battery technology, design methodologies, avionics architectures and algorithms, materials and structural concepts, propulsion system performance prediction, and others. The results of prototype vehicle designs and flight tests are discussed in the context of their usefulness in defining and validating progress in the various technology areas. Further areas of research need are also identified. These include the need for more robust operating regimes (wind, gust, etc.), and continued improvement in payload fraction vs. endurance.
\end{abstract}

\section{Nomenclature}

UAV = Unmanned Aerial Vehicle

fps $\quad=$ feet per second

RPM = Revolutions per minute

$\mathrm{J}=$ advance ratio $(\mathrm{V} / \mathrm{nD})$

$\mathrm{V} \quad=$ velocity (fps)

$\mathrm{n} \quad=$ revolutions per second

$\mathrm{D}=$ propeller diameter

Ct $=$ propeller thrust coefficient $C t=\frac{T}{\rho * n^{2} * D^{4}}$

$\mathrm{Cq}=$ propeller torque coefficient $C q=\frac{\text { Torque }}{\rho * n^{2} * D^{5}}$

$\eta=$ propeller efficiency

$\rho \quad=$ air density

$\mathrm{T}=$ propeller thrust

BART $=$ Basic Aerodynamics Research Tunnel

\section{Introduction}

$\mathrm{T}$ oday's small UAVs are the result of an evolution in the various enabling technologies that compose the vehicle and the processes used in its design. These technologies include power storage improvements, innovative motor design, avionics miniaturization, design and optimization techniques, and others. Evolution in each of these areas as they apply to the small UAV are discussed below.

\footnotetext{
${ }^{1}$ Head, Small Unmanned Aerial Vehicle Laboratory, Langley Research Center, Hampton, VA, Member AIAA.

${ }^{2}$ Aerospace Engineer, Langley Research Center, Hampton, VA, Member AIAA.

${ }^{3}$ Senior Controls Researcher, Langley Research Center, Hampton, VA, Member AIAA.

${ }^{4}$ Senior Engineer, AFRL/VA, WPAFB, OH, Member AIAA.

${ }^{5}$ Senior Engineer, AFRL/VA, WPAFB, OH, Associate Fellow AIAA.

${ }^{6}$ Aerospace Engineer, AFRL/VA, WPAFB, OH, Member AIAA.
} 


\section{Power Storage Improvements}

Many small UAVs are electrically powered. Furthermore, for these electrically powered vehicles, the power storage system, in most cases a battery, represents the largest component by weight in the vehicle. Improvements in power storage represent the largest "target of opportunity" to decrease the weight of the vehicle and/or improve the performance. Table 1 shows an evolution of rechargeable batteries used as the primary power source for several small UAVs. While in general it can be said that chemistry improvements provide weight savings, other factors may influence whether there is a net gain. For example, in the case of recent developments in rechargeable Lithium based batteries, the radio-controlled model aircraft demands for higher current draw batteries has caused a decrease in the total storage capacity for a given weight. Such tradeoffs are useful for applications such as 3-D aerobatic aircraft where run time is limited and thrust-to-weight is a primary motivating factor. However, for longer endurance UAVs, the surge current requirement is likely to be far less than $5 \mathrm{C}$ so there would be a net penalty involved in using the higher current draw rated battery. As battery chemistry and manufacturing technologies improve, they will need to be focused on the small UAV application needs in order to provide an overall improvement to the vehicle system. Testing will also be required to ensure that these new battery types are capable of withstanding the duty cycles intended for UAV applications ${ }^{5}$

\begin{tabular}{|l|r|r|r|r|r|}
\hline Table 1. Battery Pack history. & $\begin{array}{l}\text { Nominal } \\
\text { Date } \\
\text { Manufactured }\end{array}$ & $\begin{array}{l}\text { Capacity } \\
\text { Voltage }\end{array}$ & Wh) & $\begin{array}{l}\text { Energy } \\
\text { density } \\
\text { W-h/kg) }\end{array}$ \\
\hline & & & & & \\
\hline Nickel Cadmium & 1990 & 10 & 1.5 & 410 & 36.59 \\
\hline Nickel Metal Hydride & 2003 & 12 & 3 & 590 & 61.02 \\
\hline Li-Ion AA cells & 2001 & 12 & 3.4 & 288 & 141.67 \\
\hline Li-Ion Cylindrical cells & 2006 & 7.4 & 2.9 & 174 & 123.33 \\
\hline Li-Poly 3C rated cells & 2003 & 10.5 & 3.3 & 201 & 172.39 \\
\hline Li-Poly 10C rated cells & 2005 & 11.1 & 8 & 486 & 182.72 \\
\hline Li-Poly 25C rated cells & 2007 & 11.1 & 6.2 & 492 & 139.88 \\
\hline
\end{tabular}

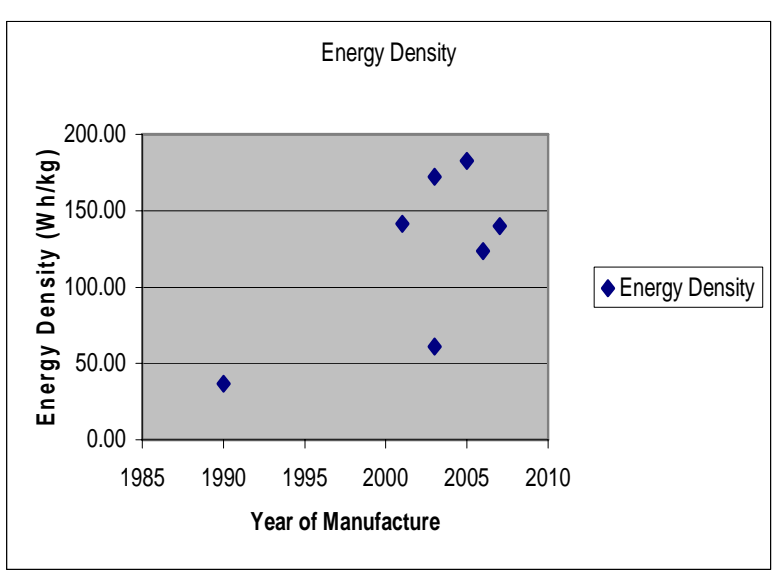

In looking forward, there may be a practical limit to the use of secondary batteries as the primary power source for the UAV. For example, there is a practical limit on the total vehicle weight for hand launching simply due to human factors issues. As such, the vehicle weight cannot grow regardless of desired endurance. When this happens, alternate energy storage systems, such as primary batteries or fuel cells, must be used.

\section{Electric Motor Evolution}

In addition to power storage evolutions, the primary propulsion means have also undergone an evolution. Figure 1. shows a picture of three electric motors designed for a similar application but using different technologies. The motor on the left is a "traditional" brushed motor and gearbox circa 2001 that has a mass of 269g. The middle motor is a brushless motor replacement which has a mass of $209 \mathrm{~g}$, a savings of $22.3 \%$. The motor on the right is an "outrunner" motor or external can motor which drives the propeller directly. This high torque motor eliminates the necessity for a gearbox thus providing a further weight savings of $13.3 \%$ over the inrunner brushless motor. Also seen is as a reduction in the number of moving parts, enhancing its reliability. Costs for these improved motors also seem to be decreasing as their utility becomes more widespread amongst mass-market users.

One potential drawback to the outrunner motor appears in the form of integration. Since the majority of the external surface is rotating, there is no direct way to attach a heat sink to aid in cooling, as would be the case for the 
other motor types. This requires more consideration for cooling airflow and the associated impacts of that flow on the overall system design.

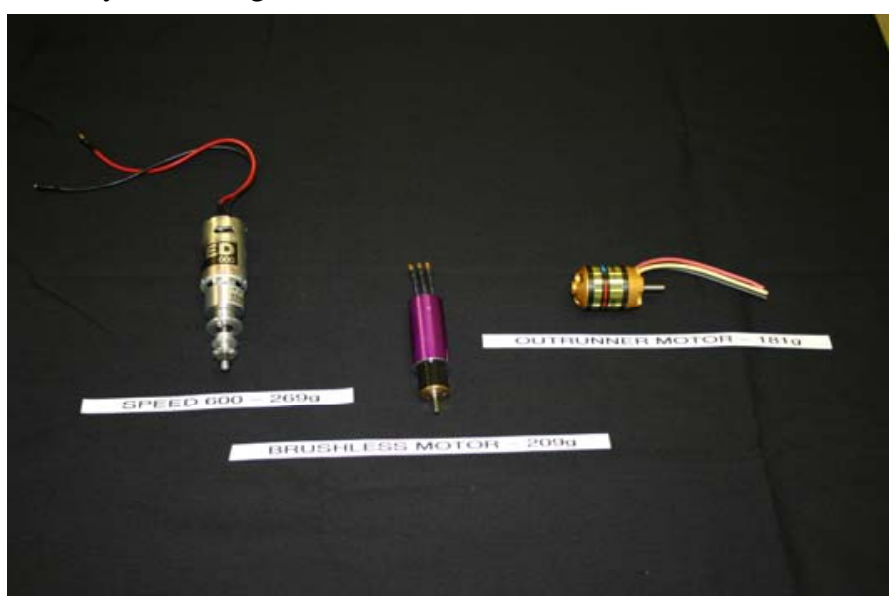

Figure 1. Similar motors using different configuration technologies.

Testing of these motors indicate that all three have similar initial performance characteristics at certain specific design points. However, the brushed motor typically degrades more rapidly with use than the other two. During a recent series of wind tunnel tests, the geared inrunner motor was tested with the same propeller as an outrunner motor of the type shown. At 60fps, the motors were consuming similar power levels (168 watts vs. 173 watts), produced similar net thrust values (1.15lb vs. 1.2lb.) and had similar propulsive system (i.e. combined motor and propeller) efficiencies (55.7\% vs. 56\%).

\section{Avionics Miniaturization}

One of the most dramatic size, weight, and power reductions for small UAV components has come from avionics miniaturization. Not only have these systems become dramatically smaller, but they have also become more capable. Table 2. shows a collection of inertial measurement systems from various time periods. Note both the weight improvement as well as functionality have risen concurrently.

\begin{tabular}{|c|c|c|c|c|}
\hline Unit & $\begin{array}{c}\text { Year } \\
\text { produced }\end{array}$ & Weight (g) & Functions & Picture \\
\hline $\begin{array}{l}\text { Exdrone 2-Axis } \\
\text { Wing leveler }\end{array}$ & 1985 & 770 & $\begin{array}{l}1 \text { gyro, wings } \\
\text { leveling only }\end{array}$ & \\
\hline $\begin{array}{l}\text { COTS } \\
\text { Autonavigation } \\
\text { 5-axis }\end{array}$ & 2002 & 159 & $\begin{array}{l}\text { 3-axis gyro, } \\
\text { 2-axis } \\
\text { accelerometer }\end{array}$ & $\frac{15}{5}$ \\
\hline $\begin{array}{l}\text { LaRC Gen1 5- } \\
\text { axis IMU }\end{array}$ & 2003 & 105 & $\begin{array}{l}\text { 3-axis gyro, } \\
\text { 2-axis } \\
\text { accelerometer, } \\
\text { airspeed, } \\
\text { altimeter, GPS }\end{array}$ & $\frac{5}{2}$ \\
\hline $\begin{array}{l}\text { LaRC Gen2 6- } \\
\text { axis IMU }\end{array}$ & 2004 & 54.5 & $\begin{array}{l}\text { 3-axis gyro, } \\
\text { axis } \\
\text { acclerometer, } \\
\text { airspeed, } \\
\text { altimeter, GPS, } \\
\text { microphone, } \\
\text { temperature }\end{array}$ & 20875: \\
\hline
\end{tabular}


Continued improvement from technologies such as micro-mechanical machines (MEMS) appear to be accelerating more functionality into smaller form factors. For example, the MEMS devices being used in Figure 2. are all single-element devices, i.e. one axis gyro or accelerometer. MEMS devices are currently available which package 3-axis accelerometer or dual-axis gyros in a single chip. This added functionality can either be used directly to lower the part count and board surface area or it can be used to provide redundancy to improve reliability. Other types of microelectronics, such as counters (for measuring RPM), analog-to-digital converters, sensors (pressure, temperature), and others are also benefiting from advances in packaging and microcontroller improvements.

\section{Design Improvements}

Several improvements of a general nature have occurred in the last few years which have application to small UAVs. Widespread commercial availability of inexpensive yet robust materials such as Expanded Poly-Propylene (EPP), have served to offer the convenience of simple homogeneous structures with the durability of core-sheeting multi-layered structure. In some cases, other foam types, beyond the traditional expanded polystyrene (EPS) foams have begun to be used as primary structure. These foams include Depron, Zepron, Arcel, extruded polystyrene, and polyurethane foam types.

Design methods are currently being developed to help improve the design optimizations of small UAVs. Figure 3. shows a comparison of one currently available electric motor propulsion prediction code with wind tunnel data. Analysis indicates that the predicted vs. actual thrust values can vary by $+/-25 \%$. Variances in the predicted power required to generate a specific thrust value vary by a similar amount. Optimization using the predicted values could easily lead to poor optimization in the actual system.

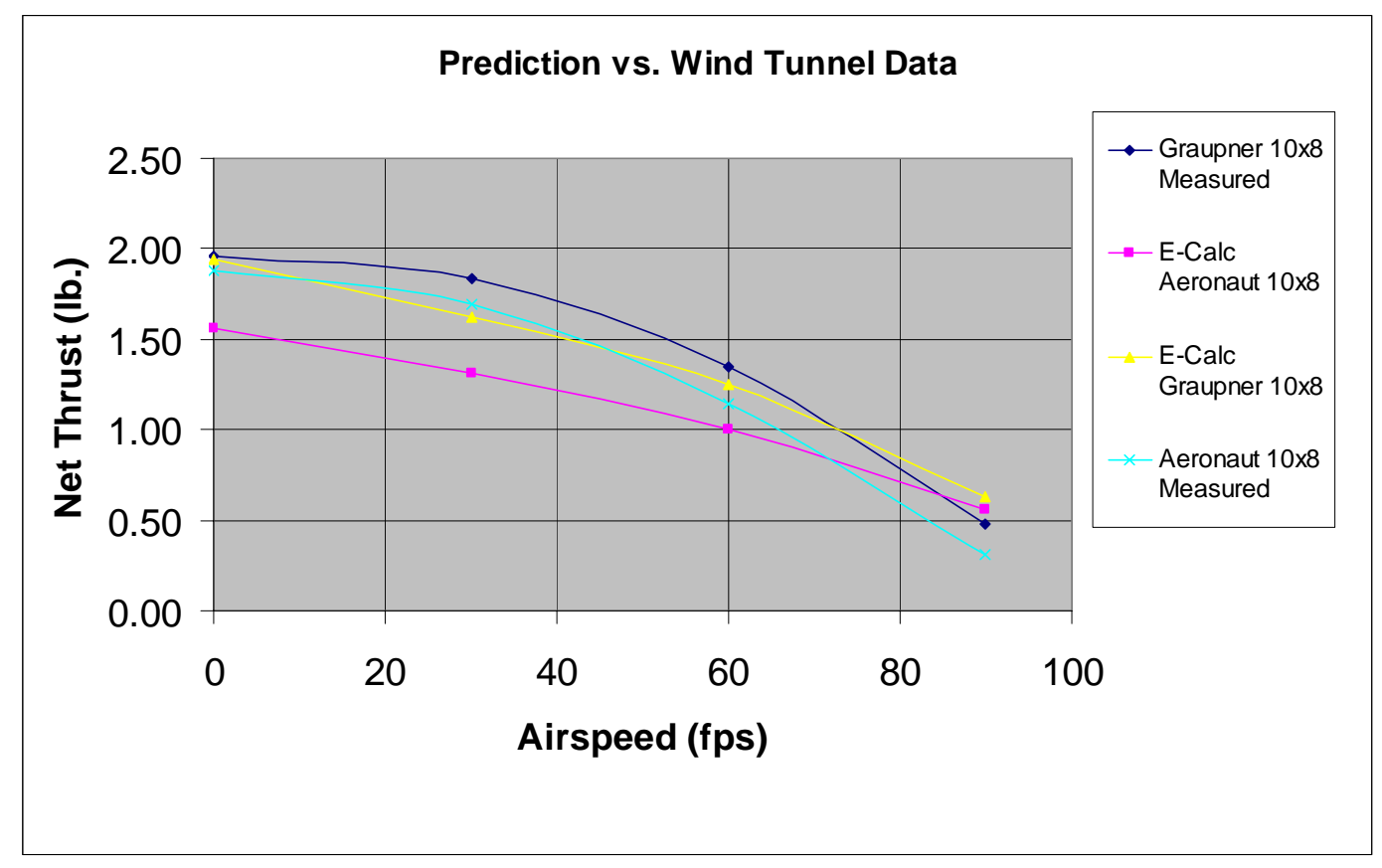

Figure 3. Comparison of predicted vs. wind tunnel measured thrust.

Development of a more robust propeller analysis and/or design capability for this class of vehicle is clearly needed. One such development is being undertaken by AFRL. Motivations for a new development include, first the need: the lack of thoroughly vetted non-proprietary propeller design codes, and the relevance of those codes to the lowReynolds number flowfields encountered by the propeller blades of small UAVs; and the means: wind tunnel and especially static thrust-stand tests of off-the-shelf propellers driven by electric motors are in principle straightforward and amenable to university-type experiments. Merchant and Miller ${ }^{1}$ and Brandt $^{2}$ tested large collection of off-the-shelf propellers designed for radio-controlled hobby aircraft, with electric or internal- 
combustion engines. The present work includes a related study at the Langley Aeronautical Research Center's Basic Aerodynamics Research Tunnel (BART). A standard 6-component internal balance was used to measure thrust (axial force) and torque (rolling moment) from a series of propeller-motor-speed controller combinations. These were then compared with a spreadsheet-driven analytical prediction based on momentum and blade-element theory. Figure 4 compares the BART experimental data, the analytical prediction and experimental data from BrandtError! Bookmark not defined., for the Graupner 10" diameter 8" pitch “cam slim” propeller ${ }^{3}$ designed for electric motors. The analytical prediction used blade chord distribution as reported by Brandt, and two alternative approaches to twist distribution: that reported by Brandt, and a standard twist distribution implied by the manufacturer's value of blade pitch. The prediction assumes blade sectional airfoil properties based on XFOIL ${ }^{4}$ computations for a NACA 2412 section at $\mathrm{Re}=100,000$. Such an approach is patently flawed on numerous grounds; Reynolds number will vary significantly depending on flight speed, propeller rotation speed and the blade station; the local flow disturbance intensity - which affects airfoil lift and drag considerably - is unknown; and the actual propeller blade section is unknown and itself varies with blade station. However, if the deep-stall lift and drag curves are modeled with curve fits, some experience suggests that blade section and Reynolds number effects are relatively subordinate to chord and twist distribution. That is, the accuracy of the prediction depends far more on capturing the correct chord and twist distribution, than on sectional profile and Reynolds number.

BART wind tunnel data in Figure 4 are a composite of four separate runs. Repeatability is good at every setting except zero free-stream $(\mathrm{J}=0)$, but inferior to Brandt's dataError! Bookmark not defined.. Brandt's data clusters around higher torque coefficient values than for the other data sets, thus giving a low propeller efficiency. Analytical prediction using the nominal pitch value shows excellent agreement with BART thrust coefficient data. Both analytical approaches grossly underpredict low-J torque, but prediction based on Brandt's twist data shows a good fit at higher J. Efficiency is overpredicted by analysis, due to the underprediction of torque - though, again, the fit is reasonable near the maximum values of $\mathrm{J}$.
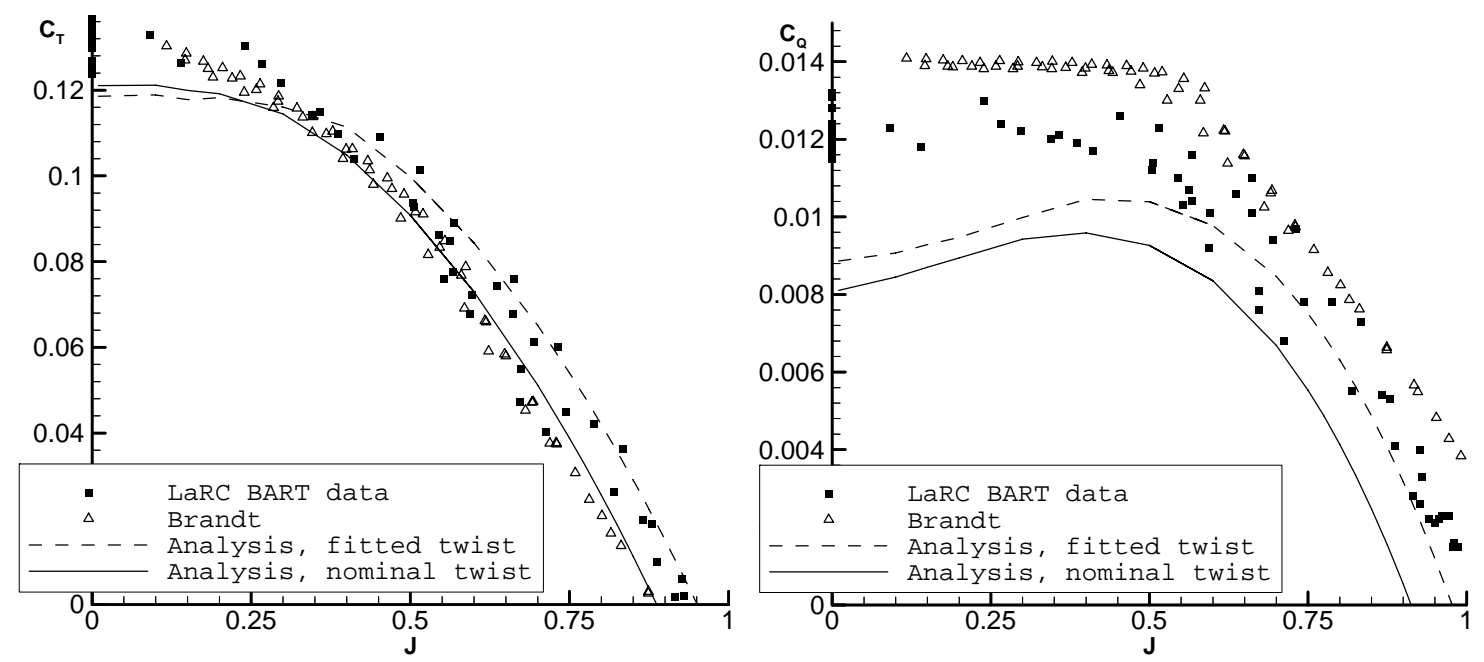

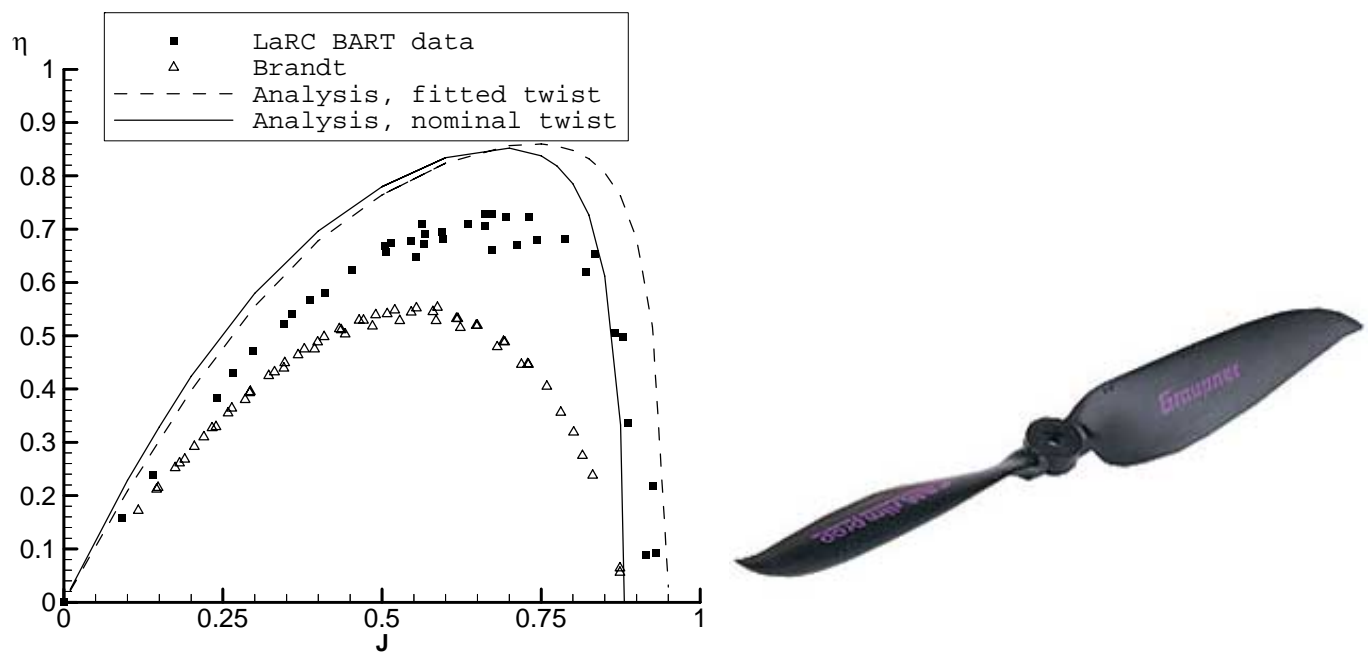

Figure 4. Wind tunnel data and analytical prediction of thrust coefficient, torque coefficient and efficiency for the Graupner 10x8 “cam slim”Error! Bookmark not defined. propeller

In addition to propulsion performance prediction methods, unique structural designs are being developed to allow more robust gust response. Figure 5 shows one of the experimental wing constructions being investigated empirically. Traditional structural analysis is problematic for this type of wing, namely, where a non-uniform adhesive (such as a foaming urethane glue) is used to bond structural reinforcements to a monolithic elastic foam structure. Locations of the tubular spar relative to the computed spanwise center of pressure line are being investigated for possible benefits of passive aeroelastic tailoring in this non-traditional structure.

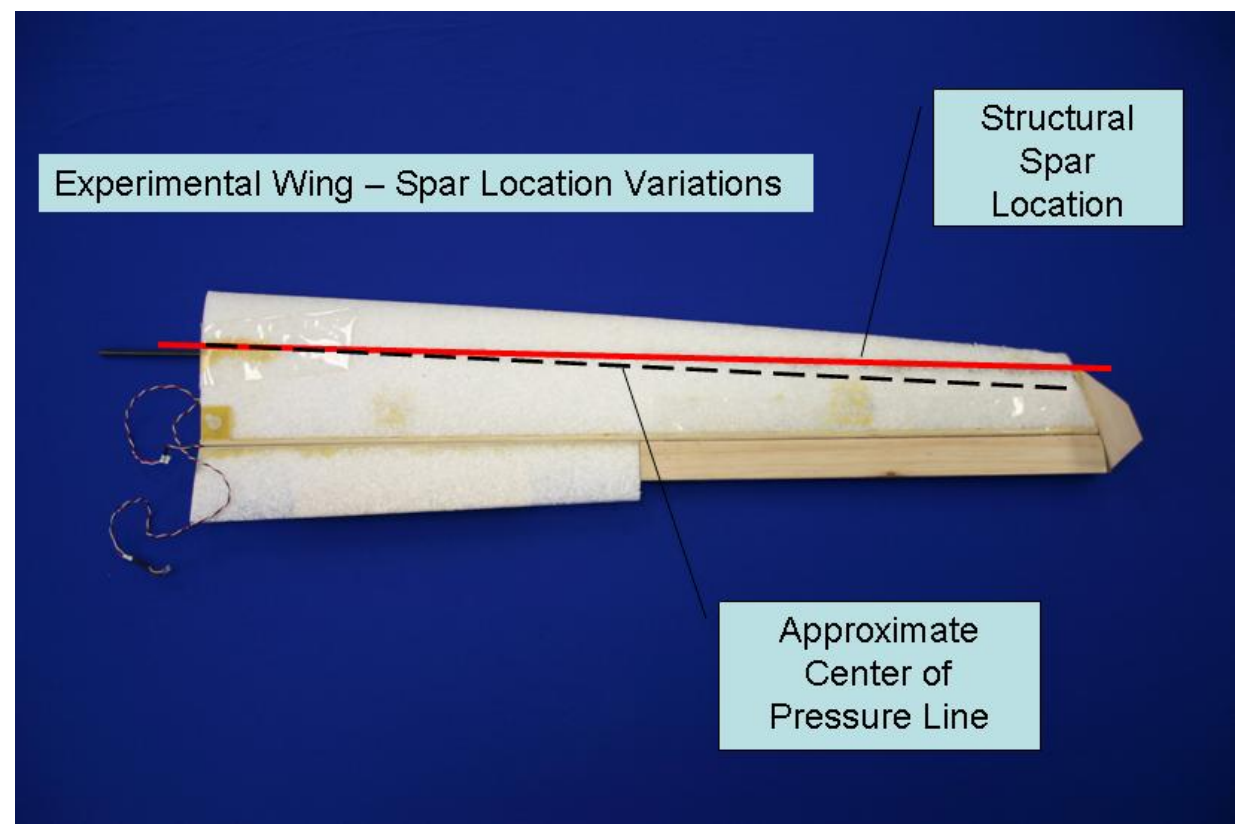

Figure 5. Experimental Wing for Spar Location Variation 


\section{Conclusion}

Small Unmanned Aerial Vehicles should continue to improve in both performance and overall functionality. Technology advancements in power storage technology, avionics miniaturization, materials, and design methodologies will enable new missions to be performed by increasingly smaller, lower cost platforms. Utilization of these enhanced capabilities, especially for commercial applications, is likely to depend on the ability to operate these platforms safely in the National Airspace System.

\section{References}

\footnotetext{
${ }^{1}$ Merchant, M.P., and Miller, L.S. "Propeller Performance Measurement for Low Reynolds Number UAV Applications". AIAA 2006-1127, 2006.

2 Brandt, J.B. "Small-Scale Propeller Performance at Low Speeds”. M.S.E. Thesis, University of Illinois at UrbanaChampaign, 2005.

${ }^{3}$ http://www.graupner.de

${ }^{4}$ Drela, M. XFOIL Users Guide, Version 6.94 , MIT Aeronautics and Astronautics Department, 2002.

${ }^{5}$ Reid, Concha; Manzo, Michelle; Logan, Michael J.; "Performance Characterization of a Lithium-Ion Gel Polymer Battery Power Supply System for An Unmanned Aerial Vehicle”, SAE Paper 2004-01-3166, Power Systems Conference, November 2004, Reno, NV, USA.
} 